\title{
A Comparison between Different Central Frequencies of Investigation in Buried Utility Detection through GPR: a Study Case
}

\author{
L. Bianchini Ciampoli, A. Benedetto, L. Pajewski \\ Department of Engineering, Roma Tre University \\ Via Vito Volterra 62, 00146, Rome, Italy \\ luca.bianchiniciampoli@uniroma3.it, \\ andrea.benedetto@uniroma3.it, \\ lara.pajewski@uniroma3.it
}

\author{
A. M. Alani, F. Tosti \\ School of Computing and Engineering, \\ University of West London (UWL) \\ St Mary's Road, Ealing, W5 5RF, London, UK \\ Amir.Alani@uwl.ac.uk, \\ Fabio.Tosti@uwl.ac.uk
}

\begin{abstract}
Ground Penetrating Radar (GPR) has proved to provide a high reliability in detecting several subsurface features such as water and gas pipes, energy and telecommunication supplies, water reservoirs or air voids. The present work uses a comparison between different central frequencies of investigation to reconstruct the network of utilities located underneath a paved surface and to understand the best strategy of analysis to undertake. To this purpose, a $757 \mathrm{~m}^{2}$ paved carpark situated in London was used as test site and divided into three smaller areas. Central frequencies of investigation of $250 \mathrm{MHz}, 400 \mathrm{MHz}, 500 \mathrm{MHz}, 1000 \mathrm{MHz}, 2000$ MHz, and $4000 \mathrm{MHz}$ were selectively employed over these areas, and the outcomes from the $250 \mathrm{MHz}, 500 \mathrm{MHz}$, and 1000 $\mathrm{MHz}$ are here analyzed. The analysis of the data has detected the presence of several utility lines with placements different from those represented within the design charts. Useful insights about the performances of different central frequencies of investigation are here discussed, as well as the usefulness of GPR in validating information collected by visual inspections and available from cartographic maps.
\end{abstract}

Index Terms-GPR, Ground Penetrating Radar, utilities detection, frequency of investigation.

\section{INTRODUCTION}

Prior to the start of any underground work it is crucial to gather all the available information about what lies beneath the ground surface, in order to avoid possible interferences between the directional drills and the existing underground utilities network or obstacles [1]. In the last decade, utilities owners and construction, building, and maintenance companies went through several legal trials caused by unexpected interferences between underground networks and excavation activities, which have pushed many public administrations to tackle this issue through legislative acts and dedicated standards for accurate and preventive utilities detection [2]-[4]. According to the current state of the art, the information arising from the available cartographies and maps is usually coupled with that acquired by pipes and cables locators. Such devices, based on electromagnetic (EM) induction, can perform well when accurately locating electricity conducting pipes or cables, but they cannot recognize non-metallic targets, which represents their major drawback.

Amongst the non-destructive technologies (NDTs) available for this purpose, Ground Penetrating Radar (GPR) has certainly performed the most reliably. Such a method, sensitive to the dielectric inhomogeneities of materials, allows recognition of utilities networks regardless of the material of the pipes, and holds a key role in effectively detecting underground targets even without any prior knowledge of their location [5], [6].

This paper presents the first promising results of an extensive work aimed at defining the best survey configuration by comparing a set of data collected with different GPR systems.

\section{THE STUDY CASE}

\section{A. Introduction}

The objective of the study is to find a solution to ambiguities and uncertainties arising from resolution/penetration issues. Namely, does an optimal frequency of investigation exist? To this purpose, is it effective to integrate different systems?

This issue was tackled during the three-day Training School "Ground Penetrating Radar for road-pavement assessment and detection of buried utilities" held in October 12-14, 2015, at the University of West London (UWL), in London (UK), and organized within the framework of COST Action TU1208 "Civil Engineering Applications of Ground Penetrating Radar". This work originates in the context of this School and is based on the results of an experimental activity which will be described below.

\section{B. The survey site}

According to the aforementioned, three EM tests (i.e., Test 1, Test 2 and Test 3 ) were performed over three rectangular areas, located on the paved surface of a carpark at the St Mary's building of the UWL (Fig. 1a). Such areas were delimited and signed with regular-pattern grids, and selected for intercepting different types of utilities, such as gas pipes, Low Voltage (LV) cables, drainage systems, etc. 


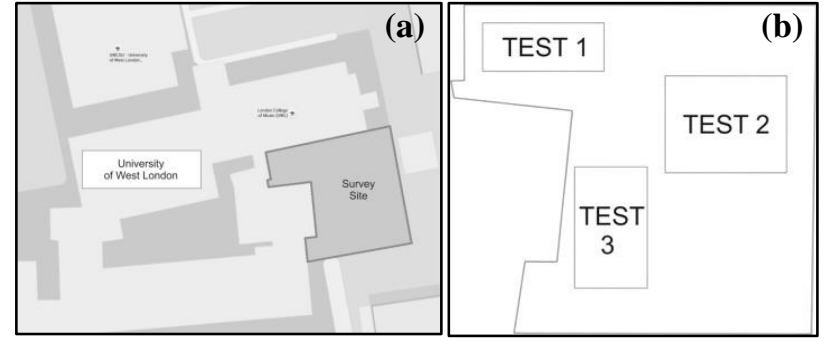

Fig. 1. The survey site, in the St Mary's building of the UWL (a), and the three surveyed areas, within the site (b)

All such information was retrieved from design drawings and available maps of buildings.

Although the various maps here consulted provided no univocal information about the accurate location of the underground utilities, they all confirmed the presence of a concrete retention tank, an LV cable network, and a siderunning cable system supplying the lighting lamps, as depicted in Fig. 2.

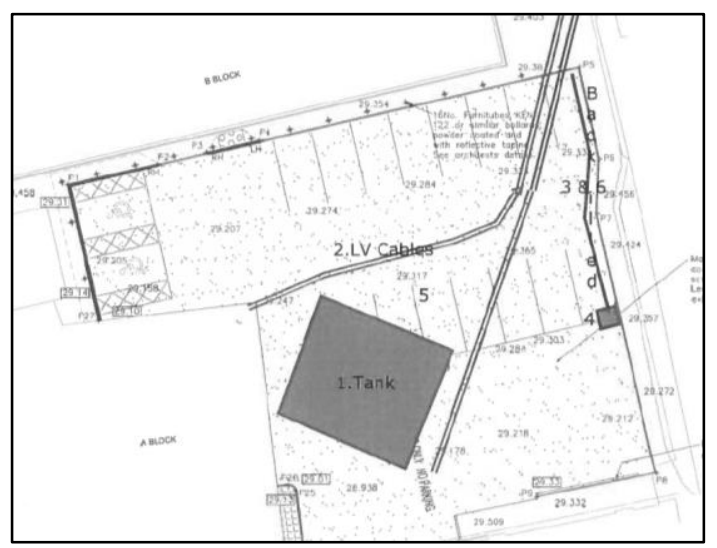

Fig. 2. Design drawing of the survey site. It is possible to identify the retention tank in the middle area, and the LV cables running at the edges of the carpark

The first grid wherein Test 1 was carried out, covered a $4 \mathrm{~m} \times 10 \mathrm{~m}$ area and was located at the north-west corner of the carpark. In Test 2 , a second grid of $6 \mathrm{~m} \times 7 \mathrm{~m}$ was located in the middle area of the carpark. Lastly, Test 3 was performed over a third grid of $5 \mathrm{~m} \times 8 \mathrm{~m}$ in the south-west part of the carpark.

The comparison between Fig. 2 and Fig. 3 shows the level of uncertainty existing when employing drawings and maps for reconstructing the underground network of buried utilities. As an example, mismatches can be easily seen in the location of the retention tank.

More information about the possible presence of further buried utilities was investigated by checking whether the paved surface was subjected to any excavations after the construction of the carpark.

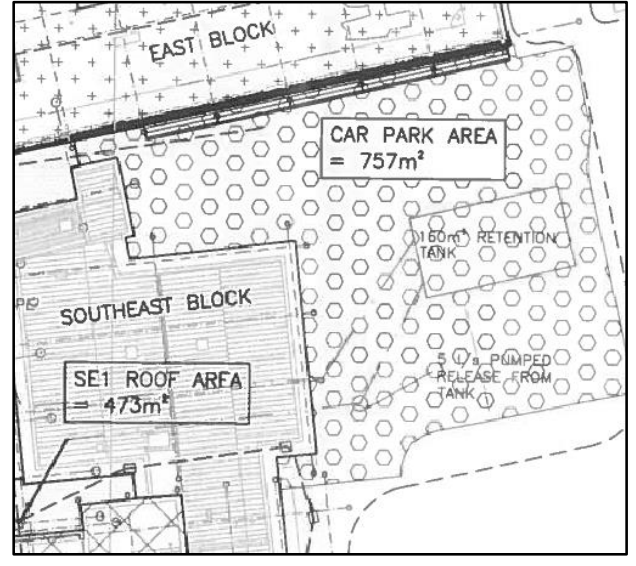

Fig. 3. Map of the surveyed carpark. The position of the retention tank turns out to be significantly different from what is represented in Fig. 2

In general, the significant level of uncertainty encountered in the various consulted cartographic supports highlights the important role played by GPR in disambiguating such information.

\section{Test equipment}

With the aim of evaluating the usefulness of an integrated investigation, different pulsed ground-coupled GPR devices, all manufactured by Utsi Electronics Ltd, were employed over the three aforementioned grids.

In particular, Test 1 was carried out using a radar system operating with a 3-channel configuration and central frequencies of $250 \mathrm{MHz}, 500 \mathrm{MHz}$, and $1000 \mathrm{MHz}$. Test 2 was performed by means of a GPR system equipped with a $400 \mathrm{MHz}$ central frequency shielded antenna, whereas for Test 3 one 8-channel high-resolution system, $4000 \mathrm{MHz}$ central frequency of investigation, was employed.

\section{DATA PROCESSING}

Regardless of the slight variations in the procedures performed as a function of the specific objective of each survey, a basic three-step processing scheme was performed for the whole data-set.

A first issue encountered during the processing of the data was the need for flipping some of the scans collected along the grid lines in order to make the direction of the scans uniform. This procedure was necessary because, to avoid wasting time, half the scans were performed in one direction, and the other half on the way back.

Subsequently, a zero-offset removal filter [7] was applied to the data. This process involves the subtraction of the average value of the amplitude over a single trace from each sample of the trace, with the aim of obtaining symmetrically distributed A-scans, fundamental for further processing steps.

Lastly, a bandpass filter was performed in order to increase the signal-to-noise ratio. The bandwidth of the filter was set to be 1.5 times the central frequency, in line with literature references [8]. 


\section{RESULTS AND SHORT DISCUSSION}

By analysing the radargrams collected in Test 1 , it is possible to recognize several features of the test area shown by visual inspections. As represented in Fig. 4, the area marked by grid 1 can be divided into two differently paved areas, namely, a brick-paved and an asphalt-paved area.

This feature can be easily confirmed by taking into account the B-scans collected along the longitudinal direction, namely, the major dimension of the test area investigated (Fig. $5)$. Indeed, regardless of the considered central frequency, it is possible to check a change in the underground configuration from around $7 \mathrm{~m}$ in the scan direction. In particular, in the range $7 \mathrm{~m}$ to $10 \mathrm{~m}$ it is possible to recognize a regular-layered pavement configuration, whereas in the range $0 \mathrm{~m}$ to $7 \mathrm{~m}$ the condition of the subsurface appears more irregular.

Fig. 4 shows more features of the surveyed area, such as the presence of a potential underground utilities network developing alongside both the longitudinal and the transversal direction. Such an insight derives from the reconnaissance of linear engineering works related to repaving works, visible at around $2.5 \mathrm{~m}$ width, and $5 \mathrm{~m}$ to 6 m length.

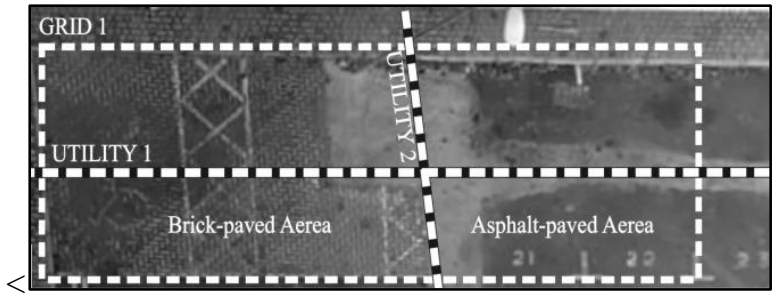

Fig. 4. Aerial view of the Test 1 area

The above hypotheses are confirmed by a tomographic analysis of the collected data. The depth of the tomographies was here determined by using a constant value of the propagating speed of the wave through the medium equal to $10 \mathrm{~cm} / \mathrm{ns}$. The utility 1 line (Fig. 4) can be recognized with the whole set of frequencies employed, at $0.45 \mathrm{~m}$ depth, approximately (Fig. 6). In order to recognize the presence of utility 2 , it was on the contrary necessary to increase the depth of inspection up to $0.93 \mathrm{~m}$. As shown in Fig. 7, it has been possible to detect a clear high-reflection track developing along the transversal direction with a significant slope, ranging between $3 \mathrm{~m}$ and $5.5 \mathrm{~m}$ length

The slope of the utility track collides with the visual inspection indicating a straight transversal direction. Moreover, due to the depth of the investigation, as the working frequency increases, the performance of the GPR system in identifying the utility track decreases, up to an actual inability to recognize any possible target with the 1000 $\mathrm{MHz}$ antenna.

In general, while a low frequency of investigation (e.g., $250 \mathrm{MHz}$ ) has provided relatively reliable information for shallower targets, the use of higher frequencies failed to identify deeper targets.
Thereby, for a general inspection wherein the depth of the target is not known prior to the survey, the use of a low frequency of investigation seems to guarantee broadly better performances.

Lastly, the results coming from the tomographic analysis of the multi-frequency data collection have only partially confirmed the hypothesis arising from the visual inspections of the surveyed area. In particular, relying on only the visual inspection could have led to a misinterpretation of both the length of utility 1 and the direction of utility 2 .
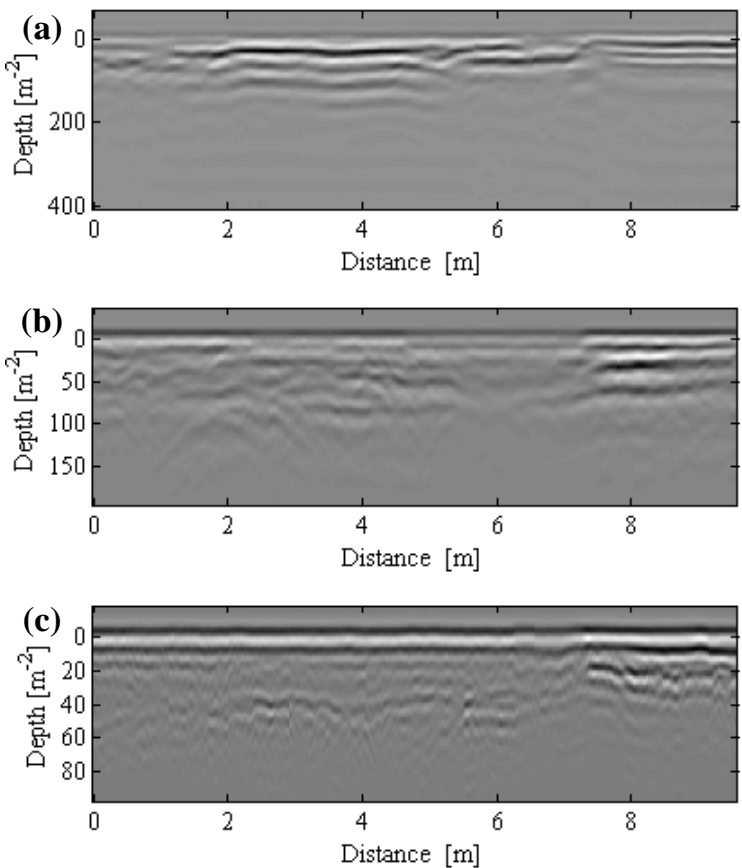

Fig. 5. B-scans collected along the longitudinal direction with $250 \mathrm{MHz}$ (a), $500 \mathrm{MHz}$ (b), and $1000 \mathrm{MHz}$ (c) central frequencies of investigation

(a)

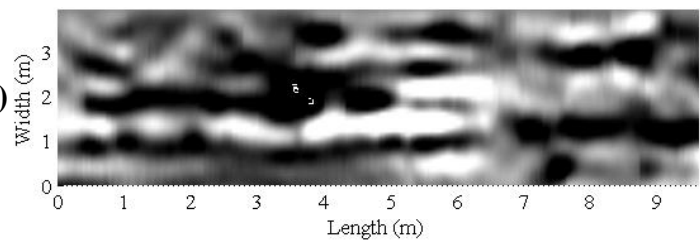

(b)

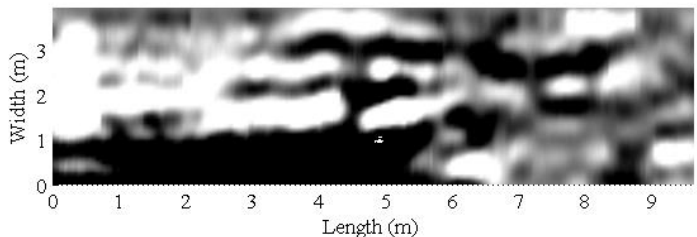

(c)

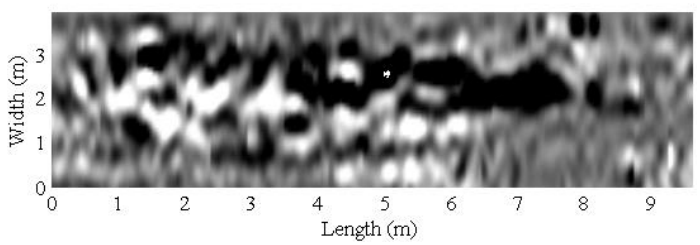

Fig. 6. C-scans collected along the transversal direction at $0.45 \mathrm{~m}$ depth with $250 \mathrm{MHz}$ (a), $500 \mathrm{MHz}$ (b) and $1000 \mathrm{MHz}$ (c) central frequencies of investigation 

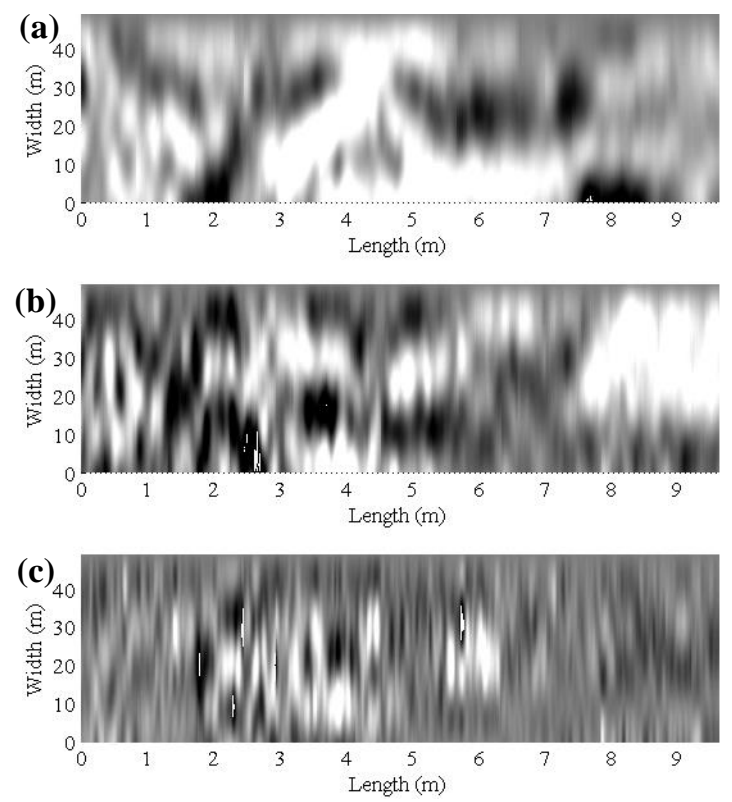

Fig. 7. C-scans collected along the longitudinal direction at a depth of 0.93 $\mathrm{m}$ with $250 \mathrm{MHz}, 500 \mathrm{MHz}$ and $1000 \mathrm{MHz}$ central frequencies of investigation

\section{CONCLUSIONS AND FUTURE PERSPECTIVES}

In this paper, the performances of several pulsed groundcoupled GPR systems in detecting underground buried utilities have been compared.

Within the context of an experimental experience carried out over a parking site at the University of West London during the Training School "Ground Penetrating Radar for road-pavement assessment and detection of buried utilities" organized by the COST Action TU1208 "Civil Engineering Applications of Ground Penetrating Radar", three equally spaced grids were surveyed with different GPR systems.

This work presents the results of a multi-frequency inspection over one out of the three grids investigated, wherein a three-channel GPR system, operating at $250 \mathrm{MHz}$, $500 \mathrm{MHz}$, and $1000 \mathrm{MHz}$, was employed.

The EM acquisition has proved to be extremely useful in confirming, modifying or integrating the information available from both design drawings and visual inspections, thereby highlighting the reliability of GPR surveys in reconstructing the network of underground utilities, especially when juxtaposed with further information.

Furthermore, the comparison between the employed central frequencies, proves how GPR systems operating at low frequencies (i.e., $250 \mathrm{MHz}$ ) perform better in recognizing the presence of utilities.

This fact pushes us towards a further consideration. Indeed, in the presence of a deep utility (as in our case), a high frequency system has showed no reliable outcomes due to its lower penetration power. At the same time, such deep utilities are typically characterized by relatively larger diameters (e.g., sewer conduits). Accordingly, a low frequency system is also not likely to be affected by resolution-related issues. In turn, in case of shallower utilities (e.g. LV cables), with typically smaller dimensions, a higher resolution is needed and so a high frequency system represents an effective choice. In line with the above considerations, the present study confirms the effectiveness of an integrated multi-frequency approach in case of a heterogeneous utility network.

Lastly, amongst the possible future perspectives related to this study, may be expected the elaboration of data related to the other 2 tests and the employment of different processing systems such as free-source or commercial software, with the main goal of defining the best configuration of central frequencies and processing systems for underground network detection.

\section{ACKNOWLEDGMENTS}

This work was developed amongst the network activities carried out within the EU funded COST Action TU1208 "Civil Engineering Applications of Ground Penetrating Radar."

In particular, the outcomes of this study have been achieved within the dual context of the COST-funded ShortTerm Scientific Mission 29169 "GPR inspections in tunnels for effective construction and maintenance of transport infrastructures" with Roma Tre University and the University of West London as reference Institutes involved, and the COST Action Training School "Ground Penetrating Radar for road-pavement assessment and detection of buried utilities", held in October 2015 at the University of West London.

\section{REFERENCES}

[1] A. Benedetto and L. Pajewski, Civil Engineering Application of Ground Penetrating Radar, Ed. Springer, 2015.

[2] French Standard NF S70-003-2, Travaux à proximité des réseaux. Partie 2: techniques de détection sans fouille/Works in the neighborhood of utilities. Part 2: Trenchless techniques of detection, 2012.

[3] Jamil, H., Nomanbhoy, $\mathrm{Z}$ and Mohd Yusoff, M.Y. "Underground utility mapping and its challenges in Malaysia", TS05 J-Mining and underground Engineering Surveying II, 5636, FIG Working Week 2012, Knowing to manage the territory, protect the environment, evaluate the cultural heritage, Rome, Italy, May 2012.

[4] N. A. Ismail, R. Saad, N. M. Muztaza and N. Ali, Predictive mapping of underground utilities using ground penetrating radar, Caspian J, Appl. Sci. Res. 2, pp. 104-108, 2013.

[5] Manacorda G., Loach P.D. Pinchbeck D., Capdevielle J.-P., Fournier P.-F., Scott H., Kazik J.J., Remeil M., The European GIGA project, Proceedings of the Tenth International Conference Ground Penetrating Radar, GPR 2004, 2004.

[6] J. Nissen, B. Johansson, M. J. Wolf and L. Skoog, Ground Penetrating Radar-A Ground Investigation Method Applied to Utility Locating in No-Dig Technologies, Mala Geoscience Raycon, pp. 1-6, 2001.

[7] A. P. Annan, Practical processing of GPR data, Sensors and Software Inc., 1999.

[8] H. Jol, Ground Penetrating Radar, Ed. Elsevier, 2009. 
